\title{
Influence of the methods of energy analysis in the decision- making along the design process
}

\author{
Influencia de los métodos de análisis energético en la toma de decisiones durante el proceso de diseño
}

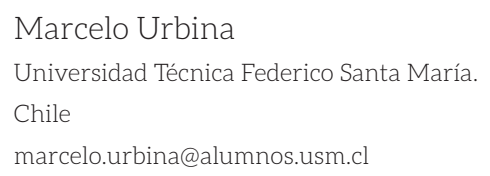

\begin{abstract}
The contemporary design process is assisted by various analytical tools that through its results influence the decision-making. This research addresses the challenge of analysing the degree of influence of the methodologies and the effects they have on the decisions taken during the different stages. For this purpose, the evolution of the design process, the components of the models for energy analysis and a case study were analysed. The results of each analysis were compared to identify which variables and stages have greater impact throughout the design process, where preliminary results show that the analysis of the effects caused by the variation of the orientation and form over the energy performance allow greater savings in the early stages.of energy generation to promote on-site installation of clean energy sources in existing buildings, to ensure a more sustainable habitat.
\end{abstract}

Keywords: Design Process, Decision-making, Uncertainty, Energy Analysis

\section{Introduction}

The lack of reliability in the methods of analysis that assist the design make difficult to take decisions on variables of function, behaviour and structure (Gero \& Kannengiesser, 2002) at different stages of the process. The tools that perform energy analysis operate under the logic of black boxes (Bernal, 2011), in other words they do not report their level of accuracy, causing an increase in the level of uncertainty in the results that validate them. In order to study the influence of the degree of definition of the variables of the energy analysis of decision-making at different stages of the design process three studies were conducted; the first one on the evolution of the design process resulting in a model that redefines the process of contemporary design; the second one on three models of energy analysis with varying degrees of accuracy resulting in a methodological model for the potential use of energy analysis tools at early stages; the third one about a case study with an emphasis on the energy analysis from which it was obtained the critical path of decision-making and analysis to history that validates it. The comparison of the results of the above mentioned studies was performed using three standard models that constitute a field of common study to analyse the influence of the degree of definition of the variables involved in the energy analysis that validated the decision making.

\section{The evolution of the design process}

After analysing different models that describe the design process from 1962 to 2002, see Table 1, four key components were identified; the design activities, the states of design, the information and the loops.

The first component corresponds to the design actions that are performed to achieve more defined states of design, like an analysis of heat balance or the adjustment of the parameters of the variable. The second component is the state of design that comparatively evaluates the effect caused by the setting of variables in the current state regarding to previous states or parallel solutions. The third one is the information related to the process, at early stages the information tends to be collected or of first order while in the more advanced ones tend to be elaborate information or of second order. The fourth component corresponds to the iteration of activities allowing the adjustment of the variables to improve performance results. The latter allows the necessary adjustments to deal with the uncertainty of the design problem. 


\begin{tabular}{|c|c|c|c|}
\hline Author & Year & Design Methods & Sequence \\
\hline C. Alexander & 1962 & $\begin{array}{l}\text { unselfconscious } \\
\text { and self-conscious } \\
\text { design }\end{array}$ & linear \\
\hline $\begin{array}{l}\text { Bruce } \\
\text { Archer }\end{array}$ & 1963 & $\begin{array}{l}\text { Basic design } \\
\text { procedure }\end{array}$ & iterative \\
\hline RIBA & 1965 & $\begin{array}{l}\text { Roadmap for } \\
\text { architects }\end{array}$ & iterative \\
\hline John Jones & 1970 & Design process & linear \\
\hline $\begin{array}{l}\text { Koberg y } \\
\text { Bagnall }\end{array}$ & 1972 & $\begin{array}{c}\text { Design process } \\
\text { archetype: Analysis, } \\
\text { Synthesis }\end{array}$ & linear \\
\hline Jane Darke & 1980 & Design process & iterative \\
\hline $\begin{array}{l}\text { Bryan } \\
\text { Lawson }\end{array}$ & 1983 & Creative process & iterative \\
\hline $\begin{array}{l}\text { Donald } \\
\text { Schon }\end{array}$ & 1984 & Reflection in action & iterative \\
\hline Nigel Cross & 1990 & $\begin{array}{l}\text { Design process of } \\
\text { four stages }\end{array}$ & iterative \\
\hline John Gero & 2002 & $\begin{array}{l}\text { Function- } \\
\text { Behaviour- } \\
\text { Structure } \\
\text { Framework }\end{array}$ & iterative \\
\hline
\end{tabular}

Table 1: Analysis of gestation of the four components in the evolution of the design process.

The design process has been transformed according to the trends of the time. In the sixties the RIBA (Royal Institute of British Architects) proposed a model called the plan of work for architects which was focused on a classic sequence of activities of analysis-synthesisdevelopment (Dubberly, 2004) while forty years later John Gero proposed the framework function-behaviourstructure model (Gero \& Kannengiesser, 2002) representing the design in a dynamic world through the behaviour of the three variables mentioned above. Both models despite belonging to different ages are described with the same components, see table 1, but use different approaches; the first one to understand the problem and the second to understand the behaviour of the problem after adjustment of any of the three variables.

\section{From the linear to the iterative}

The design process passes to be considered as a linear sequence of activities where the return to previous states was considered as an error in the planning of the design activities (Jones, 1970) to a circular sequence that allows the iteration of activities to make adjustments to achieve the desired behaviour. (Gero \& Kannengiesser, 2002)

\section{From the rational to the intuitive}

The early stages of the design process as opposed to the more advanced ones have a higher burden of uncertainty because the problem is not fully defined. It seems illogical to use in conceptual stages processes that rationally focused on a problem of which little is known (Horst, 1972). Making decisions intuitively proposing primary generators (Darke, 1979) to test solutions in a haphazard way and thus understanding the behaviour is the tendency of contemporary design processes.

\section{General model of contemporary design process}

The ability to allow adjustments at all stages is key in the process of contemporary design. The fundamental thing that the model in Figure 1 rescues is that the four building blocks operate on two levels; the product and the process. While in the product level decisions about the activities to develop supported by the states of design are taken, the level focused on the process allows adjustments that required the various states through the design iteration of certain design activities. Such adjustments are made to evaluate the impact of the variation of the parameter being analysed and compare it with earlier states of design.

This impact depends on the stage in which is e xecuted, in other words the adjustments made at earlier stages eventually have greater impact at a lower cost than those made in more advanced stages where the cost of the adjustments is greater and the impact of these is lower. (Eastman, Teicholz, Sacks, \& Liston, 2011)

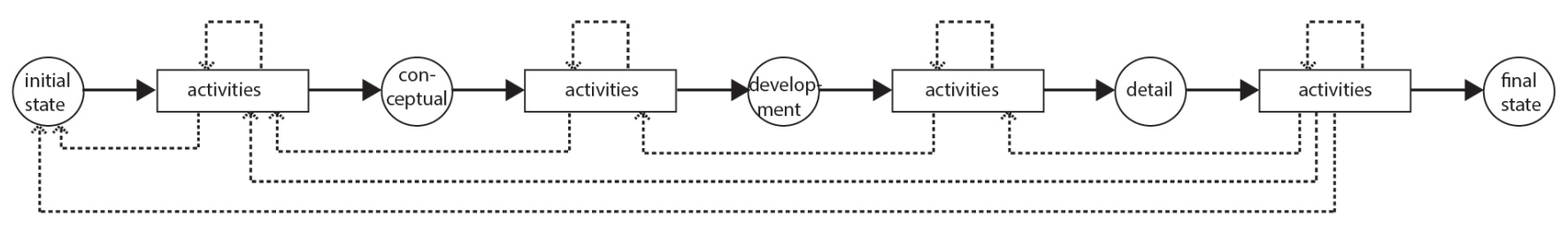

Figure 1: General model of the contemporary design process. 


\section{Energy analysis tools at various stages}

The modelling process of energy consumption through simulation tools allows optimization of resources through design strategies that focus the analysis on greater loads, where the most promising savings exists (Rosenbaum, 2003). These simulation tools deliver results that support decision-making at various stages of the process. To analyse in an isolated manner, the influence of the adjustment of the variable over the overall result a ceteris paribus methodology is used, this methodological tool is used to isolate the influence of any particular variable on this phenomenon influenced by many factors: what variables and what stage should be analysed?

The main objective of using analysis tools to assist the design is to support decision-making as these are directly influenced by the results that these tools generate. In this context an analysis focused on the variables of three energy calculation models was performed; the first model estimates the loss of a home through unsophisticated information as the area of the opaque or transparent surfaces and the thermal resistance of the material (Sarmiento, 1999). The second model calculates total losses with greater precision by including solar radiation data (Szokolay, 2004), while the third model, even more specific, accounts internal loads defined by the schedule and the type of use of the building (Sanguinetti, Bernal, El-Kaldi, \& Erwing, 2010).

The variables of an overall calculation model are classified into four groups; the building information, the local weather information, the methods of analysis and the results obtained by entering the information in the various equations or methods. During the process where the design is aided by simulation tools these variables change its roles to constants depending on the requirements of each state design and the objectives pursued by such analyzes.

\section{Support of the decision-making in advanced stages}

The later stages of the design process are the ones found with a higher level of definition, therefore constitutes the ideal time for simulation tools that assists the process to bring supposedly more reliable results that according to the logic reduce the level of uncertainty. However, this relationship is not direct, in other words with more defined information the results of the analysis generated by simulation tools are not more accurate due to the phenomenon of the black box. Moreover, the adjustments that could potentially be proposed after the analysis of the results will have a higher cost versus a slight impact on performance indicators.

\section{Support of the decision-making at early stages}

Paradoxically, in scenarios where uncertainty is greater and the design problem is loosely defined there is a potential that the adjustments have a greater impact versus the slight expense incurred to carry them out. The current methodological trend for the use of simulation tools in the early stages is to make a simple model to evaluate certain strategies to reduce the burden of energy consumption. Then they develop to explore possible solutions sequentially or in parallel to strengthen the decision-making.

\section{Methodology for using simulation tools at early stages}

During the early stages of the process, energy simulation tools can make a valuable contribution. At this stage, an expert professional could quickly assemble a simplified model of the building, a representative bucket of classrooms, laboratories, offices, or other spaces that can be used to test the effects of local weather on the building mass and the orientation of the same, in other words, two design concepts can be compared; Case 1 and Case 2 from Figure 2, and choose the concept that is closer to the goals set by the design strategy. The latter consist of performing routines such as thermal balance analysis to identify the higher loads. Then, the same analysis is performed, but with more detail, that is, first general variables such as shape and orientation are defined and then the same components increasing the level of specification.

The information linked to the model changes from variable to constant and vice versa, depending on the requirements of each state design as shown in Figure 2. The

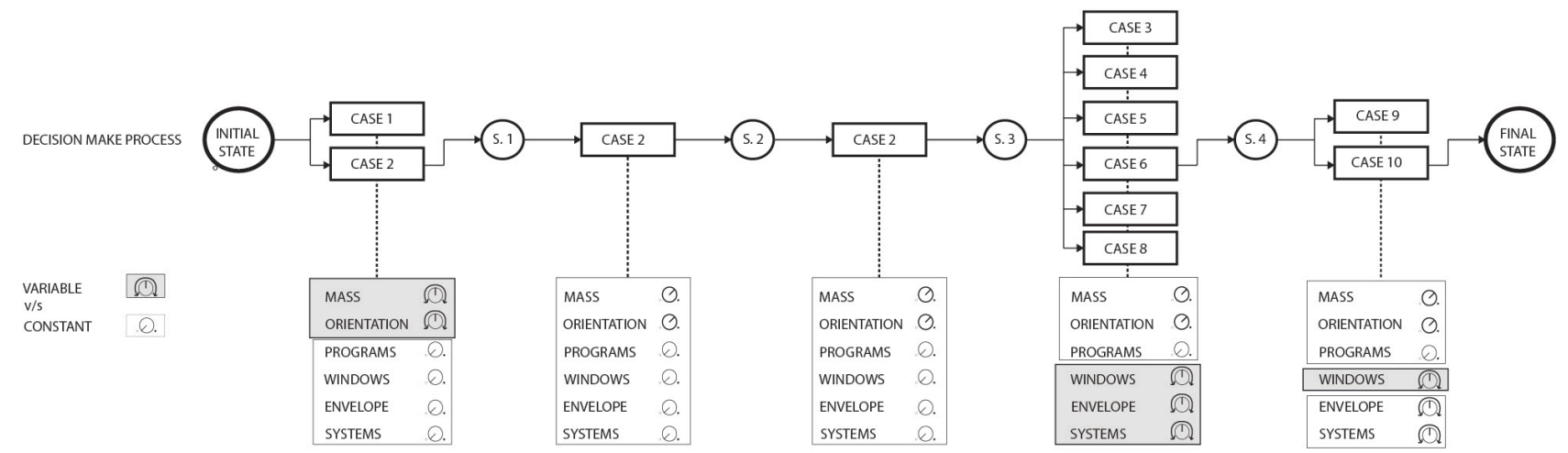

Figure 2: The process of decision-making and the variables involved. 


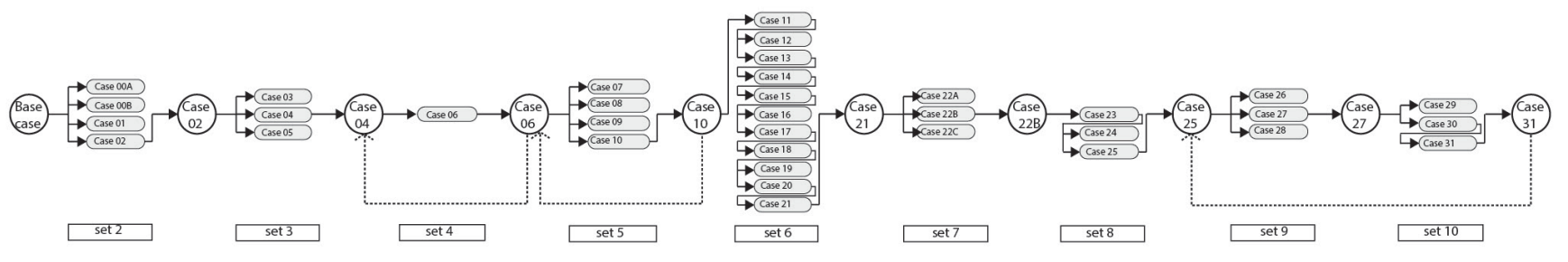

Figure 3: The process of decision-making and the variables involved

use of simulation tools strengthens the decision-making process because they can evaluate strategies we believe in and validate them through the results. However, the decision leading to making adjustments is associated with the phenomenon of false confidence due to ignorance of calculation engines of the tools that analyse the effect of local adjustments over the total energy consumption.

\section{Case study}

In order to reference the previous studies in a real case, this research examines a case study called Phoenix House (Casa FENIX), which was conceived, in the workshops of the Department of Architecture of the Universidad Técnica Federico Santa María (Hormazabal, 2014). This project describes a design process of a sustainable housing that responds to an emergency or disaster situation such as earthquakes, floods, fires, among others. This house is designed for a family of four people in the city of Valparaiso. Due to this situation, the management of energy resources is key in the design process since passive strategies are running to maintain an adequate level of comfort of the people affected. To evaluate this strategy, a simulation process through trial and error of the proposed cases is developed. With the data collected about the process of energy and thermal analysis performed with the software DesignBuilder a conceptual map that describes the critical path's decision validated by a set of cases that vary to adjust to different states of designs was elaborated.

\section{Influence of energy analysis tools in the design process of CasaFenix}

Phoenix House (Casa Fenix) performs a series of previous analysis to evaluate various aspects of design such as lighting, acoustics, building system, plumbing system, electrical system, photovoltaic system among others. The definition of some basic aspects such as lighting, deliver the data for the thermal balance simulation reporting the internal loads of the building.

The process of decision-making was supported by analysis of thirty-five cases corresponding to different variations of parameters such as wall insulation, eaves variation, variation of thermal mass, variation of hours of use, variation in architecture among others.

The cases were grouped according to the criteria and objectives. This suggests a strategic sequence of 10 set of analysis that begins with the mitigation of overheating of the windows with northern exposure through eaves to continue with a serious of adjustments in the opaque and transparent surfaces of the enclosure components. In Figure 3, two ways of taking decisions are identified, through analysis in parallel as described in set 5 and linear as described in set 4 . However, also the set of cases like the 6 and 8 that are developed in both forms of analysis are identified.

\section{Discussion}

Comparisons of the models resulting from the three studies presented above, see Figures 1, 2 and 3 indicate that besides sharing a common field where their designs states changes there is a gap between the iterative model of contemporary design and the linear model the case study develops. The uncertainty present throughout the design process is inevitable but can be mitigated by using strategies to understand the behaviour of the solution in the context of the problem and then make adjustments with the greatest potential for success. These strategies are currently being strongly supported by analysis tools that through the results they generate to validate the decision-making preferably in the most advanced stages. This assessment is reflected in the case study exposed as the results of the simulations that support the decision-making are obtained in the development stage of the design process. While in the previous stage, the conceptual one, decision-making was supported by a consensus approach from the experience of the design team. Unlike the linear model retrieved from the case study, the methods of energy analysis at early stages begins by developing simple conceptual models to inform the decisions on the resulting knowledge of a sequence of iterations that allows the adjustment of the variables to the degree of actual definition of the problem during the design process.

\section{Acknowledgments}

We would like to thank the SIGraDi Executive International Committee for providing us the basis of this formatting style. 


\section{References}

Bernal, M. (2011). Analysis model for incremental precision along design stages. 16th International Conference on Computer-Aided Architectural Design Research in Asia, (pp. 19-28). Australia.

Cross, N., \& Roozenburg, N. (1991). Models of the design Process; Integrating Across the Disciplines. Design studies , 12 (4), 215-220.

Eastman, C., Teicholz, P., Sacks, R., \& Liston, K. (2011). BIM Handbook. Hoboken: John Wiley \& Sons, Inc.

Dubberly, H. (2004). How do you design? San Francisco.

Darke, J. (1979). The primary generator an the design process. Design Studies , 36-44.

Gero, J., \& Kannengiesser, U. (2002). The situated functionbehavior-strucutre framework. Design Studies , 373-391.

Hormazabal, N. (2014). Casa FENIX. Retrieved 03 15, 2015 , from www.casafenix.cl

Horst, R. (1972). On the Planning Crisis: Systems Analysis of the "First and Second Generations".

Jones, J. C. (1970). Design Methods. John Wiley \& Sons.

Lawson, B. (1980). How designers think. Routledge.

Szokolay, S. (2004). Introduction to Architectural Science: The Basis of Sustaintable Design. Oxford: Elsevier Ltd.

Sanguinetti, P., Bernal, M., El-Kaldi, E., \& Erwing, M. (2010). Real Time Design Feedback: Coupling Performance Knowledge with Generative Design for Decision-making. In Proceedings of the 2010 Spring Simulation Multiconference (p. 192). Orlando: Society for Computer Simulation International.

Sarmiento, P. (1999). Energía Solar en Arquitectura y Construcción.

Schön, D. (1983). The reflective practitioner: How professional think in action. (B. Book, Ed.)

Rosenbaum, M. (2003). Understanding the Energy Modeling Process: Simulation Literacy 101. The Pittsburgh Papers: Best of Green-Build. 